\title{
STUDY OF THE GENETIC AND EXTRA-GENETIC DETERMI- NANTS OF ALPHA-KETOSTEROID PRODUCTION IN MAN
}

\author{
By ATTALLAH KAPPAS * AND T. F. GALLAGHER \\ (From the Division of Steroid Metabolism and Biochemistry, The Sloan-Kettering Institute \\ for Cancer Research, New York, N.Y.; and the Department of Medicine and \\ the Argonne Cancer Research Hospital, $\dagger$ of The University of \\ Chicago, Chicago, Ill.)
}

(Submitted for publication October 6, 1959; accepted December 4, 1959)

The present investigation was undertaken to evaluate the influence of heredity on steroid hormone production of man. The steroid patterns of adult male, dichorionic monozygotic triplets were examined in appropriate periods before, during and after adrenal stimulation with adrenocorticotropic hormone $(\mathrm{ACTH})$. The results of this investigation provide evidence for the existence of a significant genetic determinant of the level of steroid hormone production and metabolism, as well as an important extra-genetic influence that can modify this factor. The nature of this extragenetic influence is suggested from previous studies of physiological differences in twins.

\section{METHODS AND SUBJECTS OF STUDY}

The subjects studied ( $\mathrm{F}, \mathrm{H}$ and $\mathrm{J}$ ) were 25 year old, white, male, monozygotic triplets in excellent health. They were hospitalized during the course of the study, the essential details of which were as follows: 2 consecutive 3-day periods (Periods 1 and 2) were followed by 31 -day periods (Periods 3-5) during which each subject received intravenously $20 \mathrm{U}$ of $\mathrm{ACTH}$ dissolved in $500 \mathrm{ml}$ of normal saline over 8 hours. Care was taken to assure that equal doses of ACTH from a common lot were given over the fixed periods of time. Injections were started after breakfast and the men were kept in bed during the infusions. Following the ACTH periods, 5 consecutive 1 -day control studies were made (Periods 6-10). Four years after the first studies, Subject $\mathrm{H}$ was re-examined during a control period, followed by 3 consecutive 1 -day periods during which he received $20 \mathrm{U}$ of $\mathrm{ACTH}$ intravenously each day, over an 8 hour interval.

Complete urine collections were made during all periods and were processed generally within 48 hours after collection. Qualitative and quantitative ketosteroid patterns were determined in all periods by the methods of

* Department of Medicine, The University of Chicago. $\dagger$ Operated by the University of Chicago for the United States Atomic Energy Commission. steroid fractionation previously described $(1,2)$. Briefly, these methods include sequential and separate hydrolysis of steroid conjugates with $\beta$-glucuronidase and mild acid treatment, preparation of neutral fractions from ethereal extracts of the hydrolysates, fractionation of neutral extracts into "ketonic" and "nonketonic," and " $\alpha$-" and " $\beta$-ketosteroid" subfractions, and isolation of individual $\alpha$-ketosteroids by quantitative paper chromatography with steroid identification by infrared spectrometry when necessary.

The proof of monozygosity of the triplets was based on information derived from both fetal membrane examination and the similarity method (3). These triplets were subjects of long-term study by Sontag, Nelson and Reynolds $(4,5)$ at the Fels Research Institute for the Study of Human Development, Antioch College, Yellow Springs, Ohio, and have been carefully followed from birth. The birth membranes were carefully preserved following delivery and were examined in detail by Sontag and Nelson (4) and G. W. Streeter of the Carnegie Institution of Washington. The principal features of their description are summarized: there was a single placenta, the membranous surface of which was divided into three somewhat unequal parts by two membranous septa. On section, one of these membranes consisted of two amnions fused back to back. The other also showed two amnions but between them was another layer, evidently a much reduced chorionic septum containing remnants of blood vessels. There was no indication of fusion of two placentae. The evidence of the membranes thus indicates the monozygotic, dichorionic origin of these triplets. Similarity in a large number of physical and mental traits was also considered in establishing the single egg origin of the triplets and these have been reviewed by Sontag and Nelson (4). In addition to the physical traits described above, detailed blood typing was performed (through the courtesy of Dr. A. S. Weiner, Brooklyn, N. Y.) at the time of this study and all three subjects had identical blood reactions as follows: $\mathrm{O}, \mathrm{M}$, $\mathrm{k}, \mathrm{Rh}_{1}, \mathrm{rh}, \mathrm{P}$ and $\mathrm{F}$.

The triplets were born in the following order: $F$, weight $2.0 \mathrm{~kg}$; J, weight $1.8 \mathrm{~kg}$; and $\mathrm{H}$, weight $1.6 \mathrm{~kg}$. All three were artificially fed after birth. $\mathrm{J}$ and $\mathrm{F}$ gained well on this schedule but $H$ began to regurgitate his feedings. He gained weight slowly and the nutritional problem persisted with such severity that he was not 
expected to survive during the greater part of the first 6 months following birth. At 14 weeks, he weighed 2.8 $\mathrm{kg}$, compared with $4.1 \mathrm{~kg}$ for $\mathrm{J}$ and $4.4 \mathrm{~kg}$ for $\mathrm{F}$. At 6 months however, the gastrointestinal difficulty of Subject $\mathrm{H}$ ceased and he began to gain weight rapidly. At 2 years, $\mathrm{H}$ weighed $11.3 \mathrm{~kg}, \mathrm{~F}$ weighed $12.7 \mathrm{~kg}$, and $\mathrm{J}$ weighed $12.3 \mathrm{~kg}$; this weight ratio continued into adulthood. All three were raised together in a community of moderate size in Ohio, where they continue to live. Except for the precarious postnatal experience of Subject $\mathrm{H}$, their health has been and continues to be excellent.

\section{RESULTS}

Steroid patterns were studied in each subject during eight of the periods noted above. These were the two pretreatment control periods ( 1 and $2)$, the three ACTH periods (3-5), the postcontrol period (6) immediately following the last day of ACTH, and the postcontrol periods on the third day (8) and fifth day (10) after ACTH. During the second study on Subject $H$, steroid patterns were determined during one control day and on each of the three days on ACTH. The following abbreviations are used in the figures: A, for androsterone ( $3 \alpha$-hydroxyandrostane-17-one) ; E, for etiocholanolone ( $3 \alpha$-hydroxyetiocholane-17one); OHA, for $11 \beta$-hydroxyandrosterone ( $3 \alpha,-$

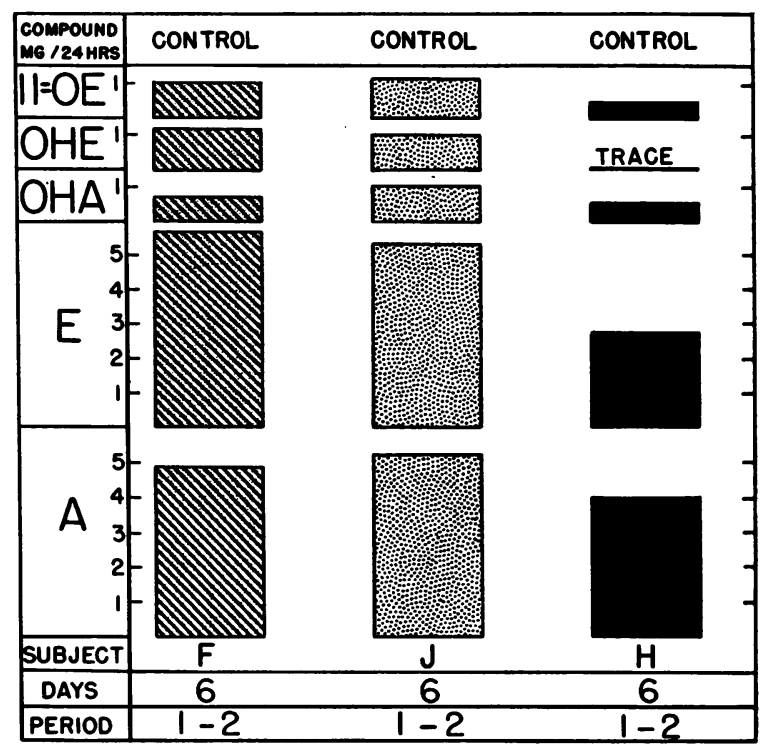

Fig. 1. Steroid patterns in adUlt Male Dichorionic IDENTICAL TRIPLETS.

$11 \beta$-dihydroxyandrostane-17-one); OHE, for $11 \beta$-hydroxyetiocholanolone $\quad(3 \alpha, 11 \beta$-dihydroxyetiocholane-17-one), and $11=\mathrm{OE}$, for 11-ketoetiocholanolone ( $3 \alpha$-hydroxyetiocholane-11,17-dione).

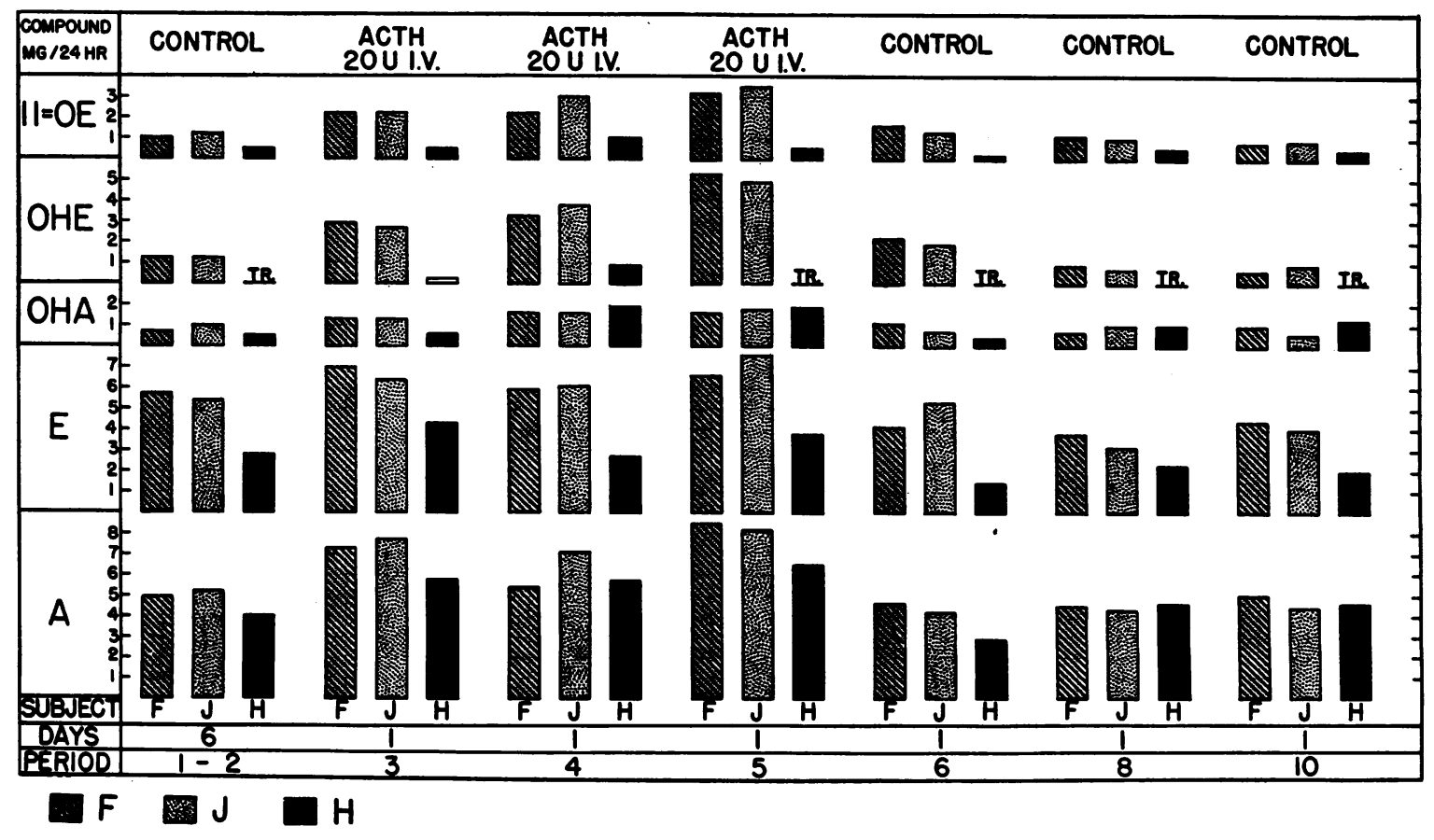

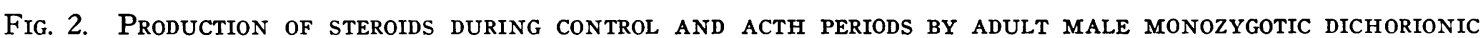
TRIPLETS. 


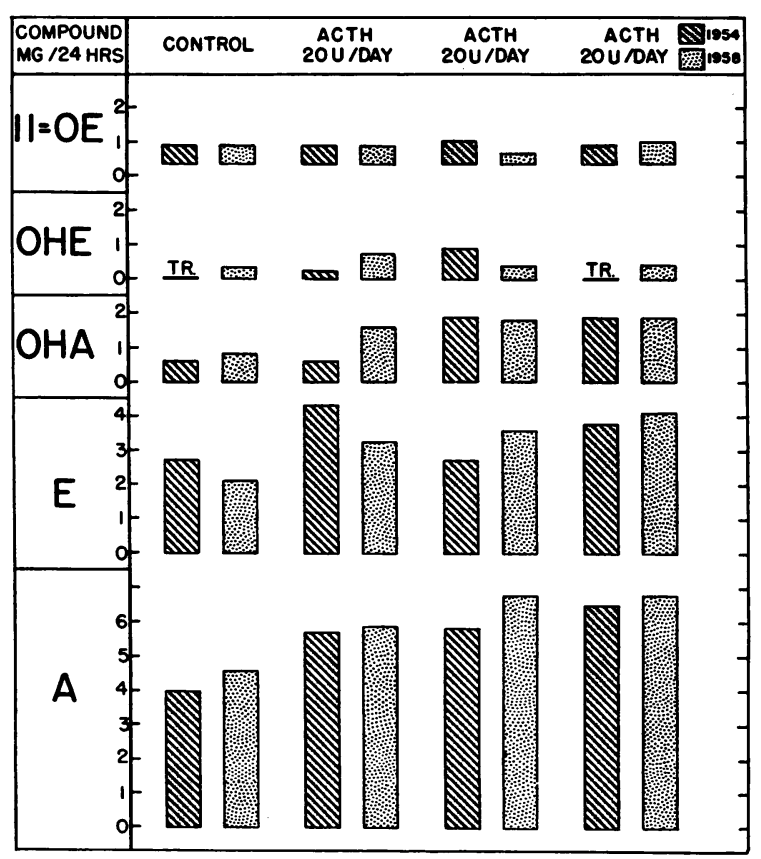

Fig. 3. Sterold production by SUbJeCt h DURING CONTROL AND ACTH PERIODS IN STUDIES MADE FOUR YEARS APART.

Quantitative values for individual ketosteroids during the two combined pretreatment control periods (Periods 1 and 2) for each triplet are shown in Figure 1. Production of 11-oxygenated and 11-desoxysteroids by $\mathrm{F}$ and $\mathrm{J}$ was essentially equivalent. Production of all these steroids by $\mathrm{H}$ was markedly lower than that of his brothers.

Figure 2 shows the ketosteroid patterns of these triplets during the three days of ACTH administration and during the various control periods. The effect of ACTH was to increase production of 11-desoxy and 11-oxygenated adrenal steroids by $\mathrm{J}$ and $\mathrm{F}$ in comparable fashion. The decline in steroid production after cessation of ACTH by these two subjects was essentially identical as well. There was a marked difference in adrenal responsiveness to ACTH demonstrated by Subject $\mathrm{H}$. Total production of 11-desoxysteroids during the ACTH periods was considerably less than that of his brothers. The 11-oxysteroids, $11=\mathrm{OE}$ and OHE, which are metabolites of cortisol, showed slight increase on ACTH administration, but this was in no way comparable with the vigorous rise exhibited by his brothers. Interestingly, OHA, which is the major metabolite of $11 \beta$-hy- droxy $\Delta^{4}$-androstene-3,17-dione (6), increased from a control level slightly less than that of his brothers to a somewhat higher level than that of either $\mathrm{F}$ or $\mathrm{J}$ during the third day of ACTH.

Figure 3 demonstrates the ketosteroid production of $\mathrm{H}$ during control and ACTH periods in an experiment conducted four years after that shown in Figure 2. The striking failure of the 11-oxygenated etiocholane derivatives to increase significantly under ACTH stimulation is once more noted and the excellent quantitative agreement with the previous values is impressive evidence for the validity of the methodology employed.

\section{DISCUSSION}

The patterns of ketosteroid production have been described in detail in previous reports from these laboratories. These steroid patterns differ quantitatively from person to person $(1,2)$ but are reproducible and constant (7) for a given individual over periods of time. Although subject to alteration by such influences as endocrine (8$10)$ and nonendocrine disease $(11,12)$ or by exogenous hormone administration $(2,8,9,13$, 14) the principal determinants of these patterns under physiological conditions apparently remain well defined. The results of the present study indicate that both genetic and extra-genetic factors play a significant role in determining the characteristics of the steroid pattern in man. The production of 11-desoxy and 11-oxygenated ketosteroids by two of the triplets ( $F$ and $J$ ) was identical, within experimental error, during all control periods and during each day on ACTH. The metabolites examined originate from at least five precursors; i.e., $\mathrm{A}$ and $\mathrm{E}$ from testosterone and dehydroisoandrosterone as well as from $\Delta^{4}$ androstene-3,17-dione (15), the probable "adrenal androgen"; OHE and $11=\mathrm{OE}$ principally from cortisol (10) ; and OHA from $11 \beta$-hydroxy $\Delta^{4}-$ androstene-3,17-dione (6). It is evident, therefore, that two of these triplets exhibited a striking similarity during all of the periods studied, not only in steroid excretion, but also in the rate and pattern of biosynthesis of steroid hormones, the release of these substances into the blood stream, and the enzymatically-determined structural transformations of these hormones to the metabolites isolated and measured. In view of the individuality 
of these patterns in normal men (1), the variable adrenal response to ACTH by different men (16), and the established monovular origin of the triplets, the striking similarity of the steroid patterns of $\mathrm{F}$ and $\mathrm{J}$ in all periods could not be attributed to chance. These data, therefore, may be considered to demonstrate the existence of an important genetic determinant of the characteristic pattern of steroid hormone production and metabolism in man.

There was a significant divergence of the steroid patterns of $\mathrm{H}$ from his brothers. Subject $\mathrm{H}$ produced smaller amounts of 11-desoxy and 11-oxysteroids during the control period (Figure 1 ), and during the administration of ACTH his steroid production failed to increase in comparable manner (Figure 2). This difference persisted through the post-ACTH control periods and was likewise demonstrable four years later (Figure 3).

These results with Subject $\mathrm{H}$ clearly indicate the existence of an extra-genetic influence operating to modify either the pattern of his steroid hormone production, or steroid hormone metabolism to the compounds isolated, or both. The intrauterine locus of action of this modifying influence is suggested by the small birth weight and subsequent deficient growth pattern of this triplet. The precise nature of this influence cannot be established with certainty, but its selective effect on Subject $H$, together with information derived from previous twin studies in man (17), permit a plausible explanation. Single egg twins may be either dichorial or monochorial with the latter sharing a mutual fetal circulation from early gestation to birth. This common prenatal circulation operates through a variety of intravascular anastomoses, and is consistently associated with a functional vascular asymmetry resulting in a disproportionate distribution of fetal blood supply to one twin partner. This asymmetry of the mutual circulation of monochorial pairs may be lethal or may result in serious handicap to the intrauterine or neonatal development of the deprived twin. Although there may be considerable postnatal recovery from this early nutritional deficit, the more frequent occurrence of physiological differences between monochorial, as compared with dichorial, single egg twins indicates that many of the effects are lasting (17).

The triplet secundines were dichorial in char- acter (4) indicating a mutual fetal circulation for two of the triplets, comparable with that of monochorial twins. In view of the circulatory imbalance of such a fetal blood supply, it can be presumed that one of this pair of triplets during gestation was consistently deprived of a fetal blood flow equivalent to that of his brothers. The small birth weight and deficient postnatal growth rate of Subject $\mathrm{H}$ make it likely that he was the handicapped member; it is suggested that his difference in production or metabolism of steroids represents a physiological aftermath of a relatively deficient fetal blood supply. This same vascular factor may indeed have proved lethal at an early stage to the anticipated fourth embryonic individual.

The nature and physiological implications of the hormonal discordance shown by Subject $\mathrm{H}$ are of interest. His steroid pattern is deficient only by comparison with his brothers. Indeed, Subject $\mathrm{H}$ compares favorably in terms of steroid production with a series of normal males of comparable age (1). However, his response to adrenal stimulation with ACTH was not only different from that of his brothers but was highly unusual when compared with the response of normal men and women $(2,13,16)$. Androsterone, etiocholanolone and 11-hydroxyandrosterone increased, clear evidence that a portion of the adrenal secretion was capable of response to a tropic hormone. There was, however, no significant elevation in the two cortisol metabolites, $\mathrm{OHE}$ and $11=\mathrm{OE}$, despite the administration of ACTH in a dose and by a route known to produce maximal adrenal stimulation (18).

This apparent impairment in response to $\mathrm{ACTH}$ may have the following basis. The inability to increase production of 11-oxygenated etiocholane metabolites during adrenal stimulation may denote a failure to enhance adrenal production of cortisol and may therefore indicate a lack of "adrenal reserve" function. This subject would thus have a superficial physiological resemblance to the patients described by Abu Haydar and colleagues (19).

In contrast to these patients, however, the capacity of Subject $\mathrm{H}$ for vigorous physical activity, including war service in Korea, was comparable in all respects with that of his brothers and contradicts the likelihood of latent hypoadrenalism. 
Alternatively, the failure to demonstrate increased production of 11-oxygenated etiocholane steroids during ACTH administration may be due to metabolism of cortisol to end products of unusual type, or to the consistent transformation of this hormone to $\mathrm{C}_{21}$ metabolites such as "tetrahydrocortisol" or the "cortols" and "cortolones" described by Fukushima and associates (20). These possibilities could not be investigated at the time of this study. If shown to occur, they would in any case only serve to emphasize the difference between Subject $\mathrm{H}$ and his brothers and affirm in effect the interplay of genetic and extra-genetic determinants of the patterns of steroid production and metabolism in man.

\section{SUM MARY}

The steroid patterns of normal adult, male, dichorionic, monozygotic triplets were examined in detail during control periods and during adrenocortical stimulation with ACTH. In two of the triplets these patterns were virtually identical before, during, and after ACTH administration. In view of the highly individual nature of these patterns, this is impressive evidence of a genetic influence on steroid hormone production and metabolism in man. The third triplet, however, produced significantly smaller amounts of individual ketosteroids, as compared with his brothers, during all periods. This finding is interpreted as evidence for the existence of an extra-genetic influence by means of which steroid production or metabolism had been modified. Related physiological differences in monochorionic twins have been attributed to demonstrated vascular asymmetry and unequal distribution of the mutual fetal circulation to one partner of the pair. The birth membranes of these triplets were dichorial in character and it is evident that a fetal situation comparable with that seen in monochorionic twins existed for two of the brothers. It is presumed, therefore, that the triplet with divergent steroid patterns was the deprived member of this pair and that his differences in production or metabolism of steroids represent a physiological aftermath of a relatively deficient fetal circulation.

\section{ACKNOWLEGMENT}

We wish to express our appreciation to Dr. L. W. Sontag, Director, The Fels Research Institute for the Study of Human Development, Antioch College, Yellow Springs, Ohio, for his assistance in this study.

\section{REFERENCES}

1. Dobriner, K. Studies in steroid metabolism. XIX. The $\alpha$-ketosteroid excretion pattern in normal males. J. clin. Invest. 1953, 32, 940.

2. Kappas, A., and Gallagher, T. F. Studies in steroid metabolism. XXVIII. The $\alpha$-ketosteroid excretion pattern in normal females and the response to ACTH. J. clin. Invest. 1955, 34, 1566.

3. Kallmann, F. J. Twin data in the analysis of mechanisms of inheritance. Amer. J. hum. Genet. 1954, $6,157$.

4. Sontag, L. W., and Nelson, V. L. A study of identical triplets. Part I. Comparison of the physical and mental traits of a set of monozygotic, dichorionic triplets. J. Hered. 1933, 24, 473.

5. Sontag, L. W., and Reynolds, E. L. Ossification sequences in identical triplets. A longitudinal study of resemblances and differences in the ossification patterns of a set of monozygotic triplets. J. Hered. 1944, 35, 57.

6. Bradlow, H. L., and Gallagher, T. F. Metabolism of $11 \beta$-hydroxy $\Delta^{4}$-androstene-3,17-dione in man. J. biol. Chem. 1957, 229, 505.

7. Dobriner, K. Studies in steroid metabolism. XX. The reproducibility of the urinary steroid pattern in humans. J. clin. Invest. 1953, 32, 950.

8. Kappas, A., Pearson, O. H., West, C. D., and Gallagher, T. F. A study of "idiopathic" hirsutism; a transitional adrenal abnormality. J. clin. Endocr. 1956, 16, 517.

9. Gallagher, T. F., Kappas, A., Hellman, L., Lipsett, M. B., Pearson, O. H., and West, C. D. Adrenocortical hyperfunction in "idiopathic" hirsutism and the Stein-Leventhal syndrome. J. clin. Invest. 1958, 37, 794.

10. Gallagher, T. F. On alterations in adrenal function, especially with adrenocortical carcinoma. Cancer Res. 1957, 17, 520.

11. Dobriner, K., Kappas, A., and Gallagher, T. F. Studies in steroid metabolism. XXVI. Steroid isolation studies in human leukemia. J. clin. Invest. 1954, 33, 1481.

12. Kappas, A., Milhorat, A. T., Rhoads, C. P., and Gallagher, T. F. A study of adrenocortical and testicular physiology in dystrophia myotonica. A preliminary report. Amer. J. phys. Med. 1955, 34, 303.

13. Kappas, A., Dobriner, K., and Gallagher, T. F. Studies in steroid metabolism. XXVII. A comparison of the steroid response to ACTH and cortisone in normal young men. J. clin. Invest. 1955, 34, 1559.

14. Hellman, L., Bradlow, H. L., Zumoff, B., Fukushima, D. K., and Gallagher, T. F. Thyroid-androgen interrelations and the hypocholesterolemic effect of androsterone. J. clin. Endocr. 1959, 19, 936. 
15. Dorfman, R. I., and Shipley, R. A. Androgens: Biochemistry, Physiology, and Clinical Significance. New York, John Wiley and Sons, 1956.

16. Dobriner, $\mathrm{K}$. Studies in steroid metabolism. XXII. The adrenal response to ACTH in young and old men. J. clin. Invest. 1954, 33, 222.

17. Price, B. Primary biases in twin studies. A review of prenatal and natal difference-producing factors in monozygotic pairs. Amer. J. hum. Genet. 1950, 2, 293.

18. Renold, A. E., Jenkins, D., Forsham, P. H., and Thorn, G. W. The use of intravenous ACTH:
A study in quantitative adrenocortical stimulation. J. clin. Endocr. 1952, 12, 763.

19. Abu Haydar, N. A., St. Marc, J. R., Reddy, W. J., Laidlaw, J. C., and Thorn, G. W. Adrenocortical insufficiency with normal basal levels of urinary 17-hydroxycorticoids: Diagnostic implications. J. clin. Endocr. 1958, 18, 121.

20. Fukushima, D. K., Leeds, N. S., Bradlow, H. L., Kritchevsky, T. H., Stokem, M. B., and Gallagher, T. F. The characterization of four new metabolites of adrenocortical hormones. J. biol. Chem. 1955, 212, 449. 